\title{
Ny publikation: Exploring the dual nature of engineering education
}

\author{
Kristina Edström \\ KTH
}

Kristina Edström (2017). Exploring the dual nature of engineering education: Opportunities and challenges in integrating the academic and professional aspects in the curriculum. Doktorsavhandling i Teknik och lärande, KTH. http://kth.diva-portal.org/smash/record. jsf?pid=diva2\%3AII $55372 \&$ dswid $=3710$

\section{PEDAGOGISK UTVECKLING SOM UTTRYCK FÖR ETT IDEAL}

Temat för avhandlingen är ingenjörsutbildningens dubbla natur. Den är samtidigt akademisk, med teori i många olika ämnen, och professionell, med förberedelse för yrkeslivet. Denna dubbelhet utgör ett ideal men är samtidigt en källa till spänningar. Temat utforskas i ett sammanhang av pedagogisk utveckling av ingenjörsutbildning, där ansatserna kan förväntas gestalta centrala ideal och erfarenheterna kan hjälpa oss att upptäcka och förstå vilka spänningar som råder. Pedagogisk utveckling har också inspirerat avhandlingen på ett mer fundamentalt plan. Eftersom utveckling handlar om avsiktlig förändring till det bättre, är det alltså en tydligt normativ verksamhet med intressenter och aktörer. Det finns en samhörighet med den kritiska forskningstraditionen där syftet inte bara är att förstå, utan också att konfrontera status quo och ifrågasätta dominerande maktpositioners legitimitet.

Pedagogisk utveckling exemplifieras här av CDIO-initiativet (Conceive, Design, Implement, Operate), ett koncept för utveckling av ingenjörsutbildning. Det bildades år 2000 av MIT, Chalmers, KTH och Linköpings universitet, och har vuxit till en internationell rörelse med I4O lärosäten. Avhandlingens kappa innehåller en beskrivning av CDIO-modellen, med exempel från KTH och Chalmers som illustrerar strävan att uppfylla idealet på program- och kursnivå i utvecklingen av ett integrerat curriculum. En analys av CDIOs strategi med integrerat curriculum visar att framgången på kursnivå begränsas av enskilda lärares förmåga att förena de teoretiska och professionella aspekterna, och att framgången på programnivå begränsas även av lärarkollegiets kapacitet för koordination, dels mellan kurs och program och dels mellan kurserna. I en av avhandlingens publikationer jämförs CDIO med PBL (problem- och projektbaserat lärande), en besläktad inriktning för utveckling av ingenjörsutbildning (Edström \& Kolmos, 20I4). En annan publikation diskuterar utvecklingsmöjligheter för CDIO med ett tydligare forskningsengagemang där kvalitetskriterierna bör kombinera användbarhet och vetenskaplighet (Edström, 20I7).

\section{PROBLEMATISERANDE ÅTERBLICKAR}

Två kritiska undersökningar syftar till att problematisera och fördjupa förståelsen av temat. Den första (Edström, 20I8) antar ett historiskt perspektiv och startar med en biografi av Carl Richard Söderberg (1895-1979), som efter examen från Chalmers emigrerade till USA för en

*Författarkontakt: kristina@kth.se

Artiklar och reflektioner är kollegialt granskade. Övriga bidragstyper granskas av redaktionen. Se www.hogreutbildning.se ISSN 2000-7558

(C)2018 Kristina Edström. This is an Open Access article distributed under the terms of the Creative Commons Attribution-NonCommercial 4.0 International License (https://creativecommons.org/licenses/by-nc/4.0/), allowing third parties to share their work (copy, distribute, transmit) and to adapt it, under the condition that the authors are given credit, that the work is not used for commercial purposes, and that in the event of reuse or distribution, the terms of this license are made clear.

Citation: Kristina Edström (2018) "Ny publikation: Exploring the dual nature of engineering education», Högre utbildning, 8(2), 87-89. http:// dx.doi.org/10.23865/hu.v8.1358 
lysande industriell karriär, följt av en akademisk karriär på MIT. CDIO-konceptet jämförs med Söderbergs idéer, som de uttrycks i hans skrifter om ingenjörsutbildning, de tidigaste från 1948. Det framkommer tydligt att spänningen mellan det akademiska och professionella är en central och mycket långlivad fråga inom ingenjörsutbildningen. Söderbergs ideal, argument och föreslagna strategier är dessutom fullt igenkännbara upp till 60 år senare i dagens diskussioner om ingenjörsutbildningens utveckling. Speciellt delar Söderberg och CDIO idealet om synergi mellan det ämnesmässiga och det yrkesförberedande, vilket innebär att spänningen inte behöver vara ett nollsummespel i curriculum. Detta leder till en kritik av metaforen "den svängande pendeln", som ofta använts för att beskriva ingenjörsutbildningens utveckling (se exempelvis Seely, 2005).

Den andra problematiserande återblicken (som återfinns i kappan) startar i berättelser om olika utvecklingsprojekt där resultaten inte har varit långsiktigt hållbara, och utbildningen har gått tillbaka till "det normala". Mönstren i erfarenheterna inspirerar till en modell, kallad organisationens gravitation, avsedd att förklara utbildningsprogrammens stabilitet. Som en följd av modellen identifieras två förändringsstrategier, kraftstrategin och systemstrategin, som kännetecknas av olika tillgänglighet, risker, resursbehov och uthållighet av resultat. En annan konsekvens är att pedagogisk utveckling kan ses som ett kompensatoriskt arbete, som är till för att stärka sådana värden som behövs för utbildningen men är otillräckligt representerade i organisationen.

\section{VILLKOR FÖR PEDAGOGISK UTVECKLING}

Båda dessa kritiska delstudier talar för att perspektivet behöver vidgas från ett fokus på utveckling av utbildningsprogrammen i sig till att även undersöka villkoren i organisationen. Med utgångspunkt i ett teoretiskt ramverk, byggt på institutionell teori och särskilt institutionella logiker, granskas hur praktiker och identiteter inom organisationen uttrycker och styrs av olika uppsättningar normer och källor till legitimitet. Två konkurrerande institutionella logiker identifieras inom ingenjörsutbildningen. Dessa kan härledas till två professioner: dels ingenjörsprofessionen, som vi utbildar för och som är förenlig med antagandet att utbildningen syftar till att utbilda nästa generations ingenjörer; dels den akademiska professionen, som lärarna tillhör och som är förenlig med antagandet att utbildningen syftar till att förmedla teori. En motsvarande spänning föreslås inom forskningen: mellan synen på universitetet som akademi, som söker kunskap för kunskapens egen skull, och synen på universitetet som public service, som söker användbar kunskap. Om den förra hänger samman med den akademiska professionens logik, har den senare flera värden gemensamma med ingenjörsprofessionens logik. Se Figur I.

Analysen visar att den akademiska professionens logik dominerar både inom utbildningen och forskningen, och får en slags dubbel hegemoni. Eftersom utbildningen och forskningen också är starkt samberoende är slutsatsen att ju mer forskningen domineras av den akademiska professionens logik, och ju mer forskningen dominerar över utbildningen, desto mer påverkas balansen i utbildningen att tippa över mot teoriundervisning, på bekostnad av den (övriga) yrkesmässiga förberedelsen.

\section{SLUTSATSER}

Spänningen mellan det akademiska och det professionella är en ren följd av ingenjörsutbildningens ideal, dess dubbla natur. De konflikter som följer är därmed olösliga, och kan bara ge mer eller mindre tillfälliga resultat. Avhandlingens argument är att det eviga skyttegravskriget om 


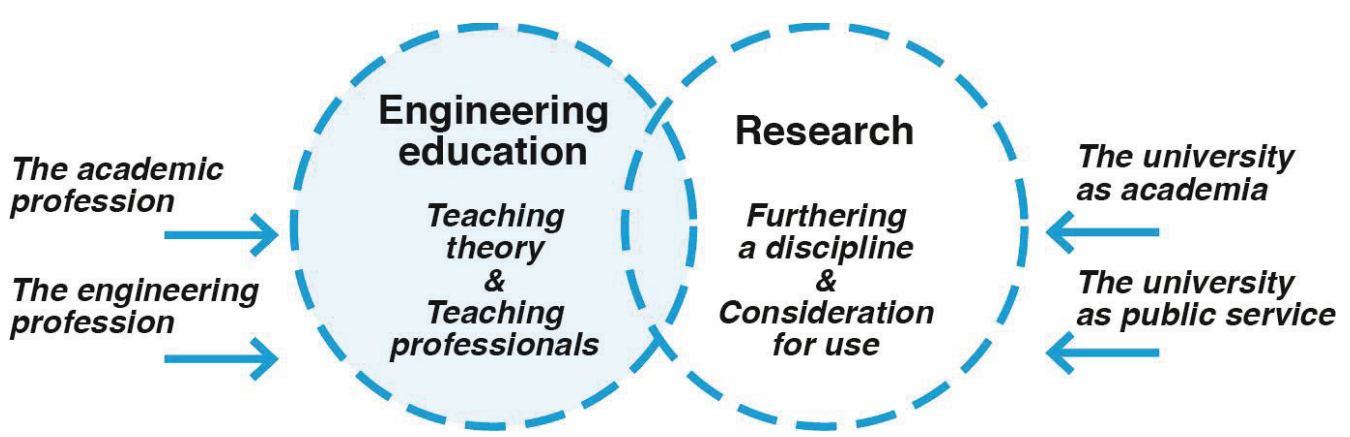

Figur I: Spänningen mellan olika konkurrerande logiker inom ingenjörsutbildningen uttryckt inom organisationens två centrala praktiker.

"hur mycket" det ska vara av det teoretiska och det professionella bör ersättas av ett upplyst arbete för att skapa en balans mellan dessa aspekter. Det behövs då arenor för kvalificerade diskussioner om ideal och spänningar samt för att identifiera produktiva lösningar. Den praktiska utvecklingen och implementeringen behöver också stöd, eftersom konflikten kommer att gestaltas i utbildningens alla praktiska frågor. Därför behövs både utveckling och forskning, men inte så att utveckling är optimistiskt handlande och forskning är kritiskt tänkande. I både forskning och utveckling finns anledning att problematisera dominerande intressen och undersöka vilka grupper som är priviligierade på andra gruppers bekostnad, och söka efter genomtänkta och produktiva lösningar. Det är möjligt, berättigat och nödvändigt att vara samtidigt kritisk och hoppfull.

\section{FÖRFATTARPRESENTATION}

Kristina Edström är civilingenjör och universitetslektor i Ingenjörsutbildningens utveckling på KTH. Hon bedriver högskolepedagogisk verksamhet även nationellt och internationellt, och har varit aktiv inom CDIO-initiativet sedan 20oI. Kristina fick KTHs pris för framstående insatser i utbildningen 2004 och valdes till livstids hedersmedlem i Tekniska Högskolans Studentkår 2009. Sedan I januari 2018 är hon chefredaktör för European Journal of Engineering Education. Kontakta kristina@kth.se för ett tryckt exemplar av avhandlingen.

\section{REFERENSER}

Edström, K. (2017). The role of CDIO in engineering education research: Combining usefulness and scholarliness. European Journal of Engineering Education, https://doi.org/10.1080/03043797.2017.1401596.

Edström, K. (2018). Academic and professional values in engineering education: Engaging with history to explore a persistent tension. Engineering Studies, 10(1), 38-65, https://doi.org/10.1080/19378629.2 018.1424860.

Edström, K. \& Kolmos, A. (2014). PBL and CDIO: complementary models for engineering education development. European Journal of Engineering Education, 39(5), 539-555, https://doi.org/10.1080/030 43797.2014.895703.

Seely, B. (2005). Patterns in the history of engineering education reform: A brief essay Educating the engineer of 2020: Adapting engineering education to the new century (pp. 114-130). Washington, DC: The National Academies Press. 